\title{
Blood flow in the foot, polyneuropathy and foot ulceration in diabetes mellitus
}

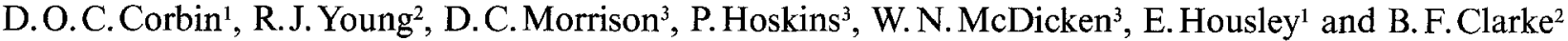 \\ ${ }^{1}$ Peripheral Vascular Clinic, ${ }^{2}$ Diabetic Department and ${ }^{3}$ Department of Medical Physics, Royal Infirmary, Edinburgh, Scotland
}

\begin{abstract}
Summary. Comparable groups of diabetic patients asymptomatic of neuropathy (Group A), with chronic painful polyneuropathy (Group B) and painless polyneuropathy causing recurrent foot ulceration (Group C) were studied for differences in pedal blood flow, peripheral somatic and autonomic neuropathy and vascular calcification. Blood flow abnormalities detected by doppler waveform analysis, and consistent with reduced peripheral vascular resistance, were found in all three diabetic patient groups. The abnormalities were of similar severity in Group A and B but generally more marked in Group C. Tests of peripheral somatic nerve function became progressively more abnormal from Group A to Group C. Autonomic neuropathy was equally severe in Groups B and C, although mild abnormalities were recorded
\end{abstract}

in diabetic patients asymptomatic of neuropathy. A similar pattern was seen for vascular calcification in the tarsal and metatarsal arteries: marked in both neuropathic groups (B and C) but mild in Group A. It was concluded that abnormal blood flow consistent with reduced peripheral vascular resistance is very common in the feet of diabetic patients whether or not they are symptomatic of neuropathy, and is most severe in those with chronic painless polyneuropathy and recurrent foot ulceration. No clear relationship was found between autonomic nerve dysfunction and the degree of abnormality of blood flow.

Key words: Blood flow, neuropathy, foot ulcers, diabetes mellitus.
There is now considerable evidence of abnormal blood flow in the diabetic neuropathic foot unrelated to lower limb ischaemia [1-6]. Clinically this is apparent as raised venous oxygen tension and distended veins on the dorsum of the foot when recumbent $[5,7]$. Blood velocity profiles against time (sonograms) recorded from the pedal arteries using doppler ultrasound suggests increased forward flow in systole and decreased reverse flow in diastole. This pattern of blood flow is consistent with a reduction in peripheral vascular resistance linked to an abnormally high degree of arteriovenous shunting within the foot $[2,5,8,9]$. The precise cause of such blood flow abnormalities and their role in pain or neurotrophic ulceration is uncertain. Sympathetic denervation is a physiologically plausible suggestion but lacks verification [10].

In this study, we have investigated blood flow patterns in the feet of diabetic patients and in non-diabetic control subjects using doppler ultrasound techniques. Doppler blood velocity/time waveforms obtained were analysed by two different methods, to derive estimates of peripheral vascular resistance which were related to the degrees of both somatic and autonomic neuropathy in three groups of diabetic patients with contrasting patterns of polyneuropathy.

\section{Subjects and methods}

\section{Subjects}

Clinical details of the three groups of diabetic patients and the one group of non-diabetic control subjects are presented in Table 1. All subjects were normotensive. Diabetic patients in Group A had no symptoms of peripheral somatic or autonomic neuropathy and no abnormal neurological signs. Patients in Group B had symptoms and signs typical of chronic painful polyneuropathy [7], while those in Group C had severe painless polyneuropathy and a history of recurrent foot ulceration. Venous blood glucose, haemoglobin and glycosylated haemoglobin (electrophoretic method, normal range $5.5-7.9 \%$ ) were measured at the time of recording.

\section{Doppler techniques}

Subjects rested supine in the horizontal position in a controlled temperature room $\left(21 \pm 1^{\circ} \mathrm{C}\right)$ for 15 to $20 \mathrm{~min}$. No recordings were made 
Table 1. The clinical details of each group are shown. Blood parameters were measured at the time of doppler recordings. Group A comprises diabetic patients asymptomatic of neuropathy, Group B patients with painful neuropathy and Group $\mathrm{C}$ patients with painless neuropathy and recurrent foot ulceration

\begin{tabular}{lllll}
\hline \multirow{2}{*}{$\begin{array}{l}\text { Group } \\
\text { characteristics }\end{array}$} & $\begin{array}{l}\text { Control } \\
\text { subjects }\end{array}$ & \multicolumn{3}{l}{ Diabetic patients } \\
\cline { 4 - 6 } & $(n=8)$ & \multicolumn{3}{l}{ Group $(n=7) \mathrm{B}(n=8) \mathrm{C}(n=7)$} \\
\hline Mean age and range (years) & 42 & 49 & 50 & 47 \\
& $(26-60)$ & $(32-60)$ & $(37-60)$ & $(32-58)$ \\
Male : female ratio & $5: 3$ & $7: 0$ & $7: 1$ & $7: 0$ \\
Duration of diabetes in years & - & 13 & 14 & 11 \\
(mean and range) & & $(1-27)$ & $(2-23)$ & $(3-21)$ \\
Insulin dependent (n) & - & 4 & 4 & 4 \\
Background retinopathy (n) & - & 2 & 6 & 2 \\
Proliferative retinopathy (n) & - & 1 & 1 & 5 \\
Random blood glucose & - & 8.8 & 11.9 & 7.6 \\
(mmol/l) & & $(3.9)$ & $(7.3)$ & $(4.6)$ \\
Glycosylated haemoglobin & - & 10.6 & 12.3 & 11.4 \\
(\%) & & $(1.4)$ & $(1.9)$ & $(3.1)$ \\
Proteinuria (Albustix) & - & 0 & 1 & 3 \\
Neuropathy & - & - & + & + \\
Foot ulceration & - & - & - & + \\
\hline
\end{tabular}

in the presence of pyrexia or active infection. Systolic blood pressure was determined at the brachial and posterior tibial arteries using a standard adult size cuff and an eight $\mathrm{MHz}$ hand-held doppler probe for auscultation. Readings were made in duplicate and the mean ankle/arm systolic pressure index calculated by combining the pressure indices from the right and left sides.

Doppler signals were recorded by a single operator from the common femoral arteries just below the inguinal ligament and from the posterior tibial arteries at the point where the artery curves around the posterior aspect of the medial malleolus. The position of the probe was adjusted until maximum waveforms were obtained. Waveforms from 10-15 cardiac cycles were recorded and stored on magnetic cassette tape (Maxell XL 2). The five most clearly recorded doppler waveforms from each artery were analysed. Pulsatility index was calculated as the peak to peak height divided by the mean area under the sonogram [11]. Allowance was made for heart rate variability by converting this 'standard' value to a 'normalised' value by dividing by the time in seconds for each pulse. Pulsatility index reflects peripheral vascular resistance; for example, in reactive hyperaemia its value is initially low but increases as distal arterioles close $[11,12]$. An overall assessment of peripheral vascular resistance was made by combining the mean pulsatility index for the posterior tibial artery from each leg.

Taking the same five waveforms, a second independent method of analysis based on mathematical modelling of blood flow in the lower limb was done. The Laplace transform model allows derivation of three parameters related to proximal resistance (Delta), arterial wall stiffness (Omega) and distal resistance (Gamma) [12-14]. The physiological and clinical application of this method is still under debate [15-20], but like pulsatility index, the magnitude of the parameter Gamma decreases in reactive hyperaemia and after intravenous papaverine [19], and so is strongly influenced by peripheral resistance. Values of Gamma derived from analysis of waveforms from each posterior tibial artery were combined to give a mean value for each patient. Any subject or patient with evidence of occlusive lower limb or aorto-iliac disease (based on clinical examination, measurement of resting ankle/arm systolic pressure index [21-23] and analysis of common femoral artery waveforms) was excluded from the study.

\section{Peripheral nerve electrophysiology}

The diabetic patients had detailed peripheral nerve electrophysiological measurements carried out using standard techniques with a thermostatically controlled radiant heater to maintain skin temperature at $32^{\circ} \mathrm{C}$. Measurements were made in the left arm and leg using a DISA 1500 electromyograph and surface electrodes. Motor nerve conduction velocity was measured in the median nerve (elbow-wrist) and peroneal nerve (knee-ankle) using supra-maximal stimuli. Sensory nerve conduction velocity was recorded orthodromically in the distal median nerve (index finger-wrist) and antidromically in the mid-sural nerve (calf-lateral malleolus). The stimulus was adjusted to give the largest evoked sensory action potential. Sensory action potential amplitude was assessed from a minimum of 64 averaged evoked potentials. Sensory conduction velocity was computed from the latency to the peak of the first negative potential.

\section{Cardiovascular autonomic function tests}

Five tests were used as previously described [24]. These were the heart rate responses to the Valsalva manoeuvre (Valsalva ratio), standing up (30:15 ratio) and deep breathing (maximum-minimum heart rate), the fall in systolic blood pressure on standing (postural blood pressure) and the rise in diastolic blood pressure during sustained handgrip (grip).

\section{Ankle and foot radiographs}

Because changes in vascular compliance due to arterial calcification might influence flow, lateral radiographs of the ankles and anteriorposterior and oblique views of the feet were taken. The presence and severity of arterial medial calcification in the tibial and pedal arteries was judged by a single radiologist who had no access to the clinical data. The severity of any medial calcification detected was graded consistently as mild, moderate or severe by reference to three selected radiographs.

\section{Statistical analysis}

The results are expressed as mean (SD) unless stated otherwise. Intergroup comparison of the doppler Laplace transform parameters and pulsatility index was performed using analysis of variance. A log transformation was performed on the values of Gamma prior to analysis. Welch's test was used when analysing posterior tibial artery Gamma and pulsatility index values because the variances in the four groups were appreciably different. When a statistically significant difference in mean values was detected $(2 p<0.05)$ the Bonferroni method was used to identify pairs of groups which differed.

\section{Results}

\section{Neurophysiological tests of nerve function}

Compared to our normal laboratory control subjects, diabetic patients in Group A had some minor abnormalities of peripheral nerve function; the most severe abnormalities were seen in Group C with Group B being intermediate (Table 2).

Cardiovascular autonomic function tests were slightly abnormal in diabetic patients asymptomatic of neuropathy (Group A) compared to our normal laboratory control subjects; however, both neuropathic groups ( $\mathrm{B}$ and $\mathrm{C}$ ) showed marked abnormalities though there was no difference between them 
Table 2. Peripheral nerve electrophysiology by group is shown along with reference ranges for laboratory

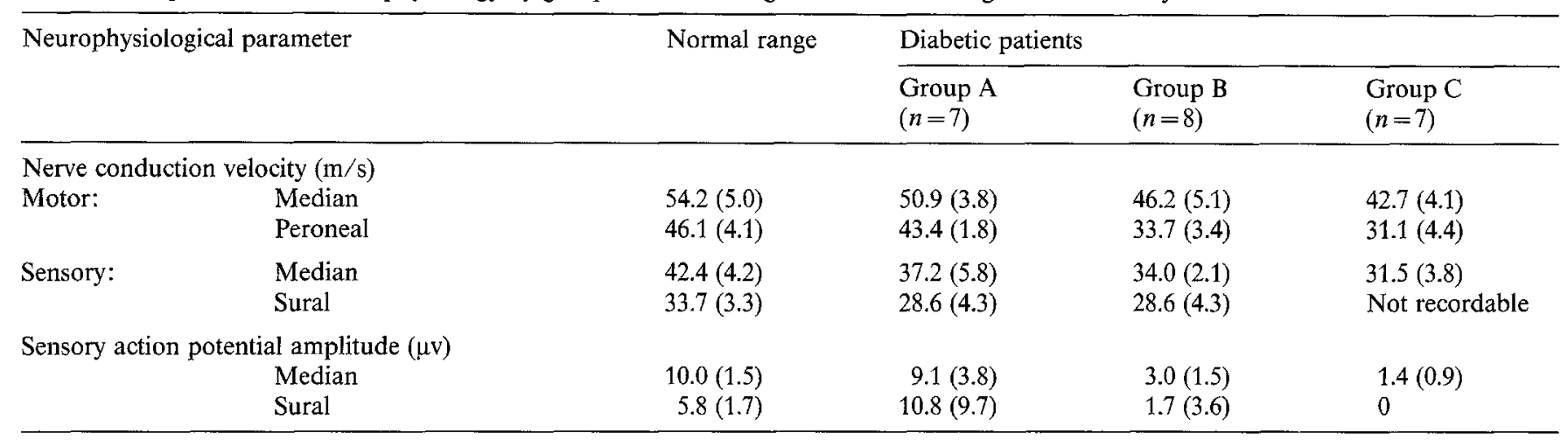

(Table 3). This pattern of abnormalities exactly reproduces our previously reported findings in a larger group of patients [25].

\section{Doppler waveform analysis}

Resting ankle pressure indices for each group are given in Table 4. The common femoral artery mean Laplace transform Delta value was 0.3 for all four groups. This value had been shown to accurately predict normal or minimally abnormal aorto-iliac segments on arteriography $[16,18]$. In the four limbs where ankle blood pressure was unrecordable because of arterial calcification, common femoral artery Laplace transform Delta values were incompatible with significant aorto-iliac disease and Gamma values were low implying that significant distal occlusion was unlikely.

The results of analysis of doppler waveforms from the posterior tibial arteries for pulsatility index (standard) and Laplace transform Gamma are shown in Figures 1 and 2 respectively. In diabetic patients asymptomatic of neuropathy (Group A), both parameters were reduced when compared to control subjects $(2 p<0.05)$. There was no difference between the diabetic patients asymptomatic of neuropathy (Group A) and those with painful neuropathy (Group B). Most diabetic patients with painless neuropathy and a history of foot ulceration had lower pulsatility indices (whether standard or normalised) and lower absolute Gamma values than diabetic patients in either Group A or B, though the group differences did not reach statistical significance (Table 5).

\section{$X$-ray abnormalities in the diabetic feet}

Sixty-five percent of tibial and 50\% of pedal arteries in diabetic patients showed arterial wall calcification (Table 6). Only one patient (Group B) had pedal without tibial artery calcification, whereas three patients in Group A had tibial artery calcification alone. More severe arterial calcification was seen in the diabetic patients symptomatic of neuropathy but there was no difference between Groups B and C. Two patients in
Table 3. The results of cardiovascular autonomic function tests are presented for each group. The reference range for the laboratory is given to the left of the table

\begin{tabular}{lcccc}
\hline Test & Normal range & \multicolumn{3}{l}{ Diabetic patients } \\
\cline { 3 - 5 } & & $\begin{array}{l}\text { Group A } \\
(n=7)\end{array}$ & $\begin{array}{l}\text { Group B } \\
(n=8)\end{array}$ & $\begin{array}{l}\text { Group C } \\
(n=7)\end{array}$ \\
\hline $\begin{array}{l}\text { Valsalva } \\
\text { ratio }\end{array}$ & $1.75(0.39)$ & $1.69(0.33)$ & $1.25(0.32)$ & $1.33(0.26)$ \\
$\begin{array}{l}30: 15 \\
\text { ratio }\end{array}$ & $1.29(0.17)$ & $1.10(0.09)$ & $1.01(0.04)$ & $1.02(0.05)$ \\
$\begin{array}{l}\text { Max }- \\
\text { min } \\
\text { heart rate } \\
\text { (beats } \\
\text { min) }\end{array}$ & $31(9)$ & $21(10)$ & $7(5)$ & $5(3)$ \\
$\begin{array}{l}\text { Postural } \\
\text { blood } \\
\text { pressure } \\
\text { (mmHg) }\end{array}$ & $-1(8)$ & $-6(6)$ & $-25(25)$ & $-33(17)$ \\
$\begin{array}{l}\text { Grip } \\
\text { (mmHg) }\end{array}$ & $30(10)$ & $32(7)$ & $21(9)$ & $19(4)$ \\
\hline
\end{tabular}

Table 4. Ankle systolic blood pressure and combined ankle/arm systolic pressure indices are shown for each group. Because of tibial artery calcification, ankle systolic blood pressure was unrecordable in some diabetic patients in groups B and C

\begin{tabular}{llllc}
\hline $\begin{array}{l}\text { Systolic } \\
\text { blood pressure }\end{array}$ & $\begin{array}{l}\text { Control } \\
\text { subjects }\end{array}$ & \multicolumn{3}{l}{ Diabetic patients } \\
\cline { 3 - 5 } & $(n=8)$ & $\begin{array}{l}\text { Group A } \\
(n=7)\end{array}$ & $\begin{array}{l}\text { Group B } \\
(n=7)\end{array}$ & $\begin{array}{l}\text { Group C } \\
(n=4)\end{array}$ \\
\hline Right ankle (mmHg) & 130.5 & 145.0 & 165.1 & 159.0 \\
& $(23.2)$ & $(19.2)$ & $(33.3)$ & $(7.4)$ \\
Left ankle (mmHg) & 130.8 & 154.1 & 163.6 & 149.2 \\
& $(14.4)$ & $(32.0)$ & $(31.7)$ & $(4.2)$ \\
Ankle/arm pressure & 1.1 & 1.2 & 1.1 & 1.1 \\
index & $(0.1)$ & $(0.1)$ & $(0.2)$ & $(0.1)$ \\
\hline
\end{tabular}

Group C also had Charcot arthropathy of the mid-tarsal joints. Each of the diabetic patients who had unrecordable ankle systolic pressures due to non-compressibility of the tibial arteries had moderate or severe medial artery calcification bilaterally. 


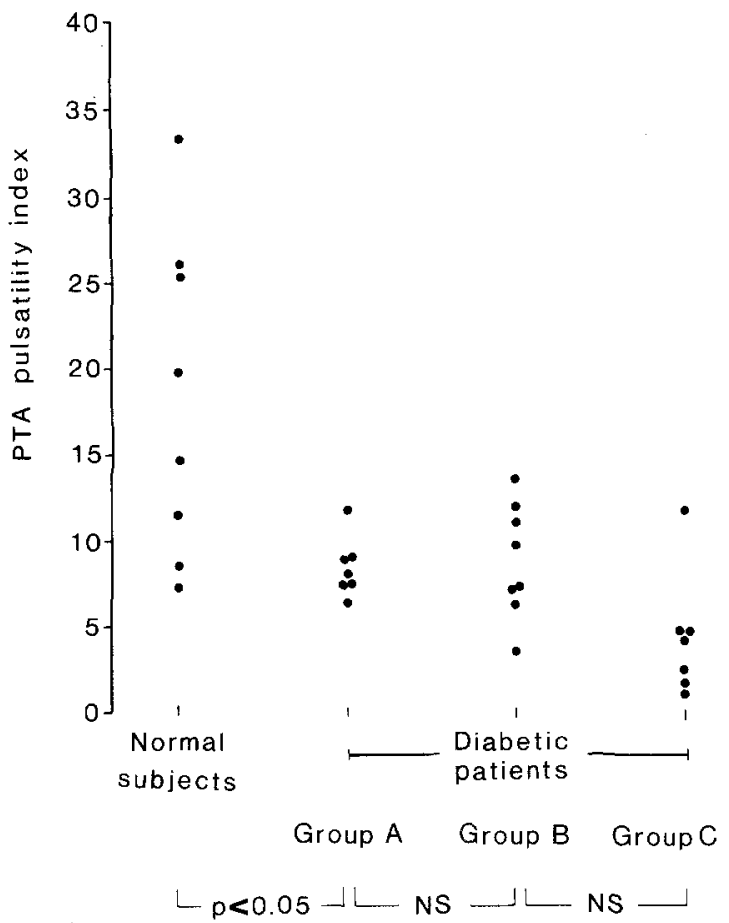

Fig. 1. Values for posterior tibial artery (PTA) pulsatility index derived by combining results from both limbs are illustrated for each group

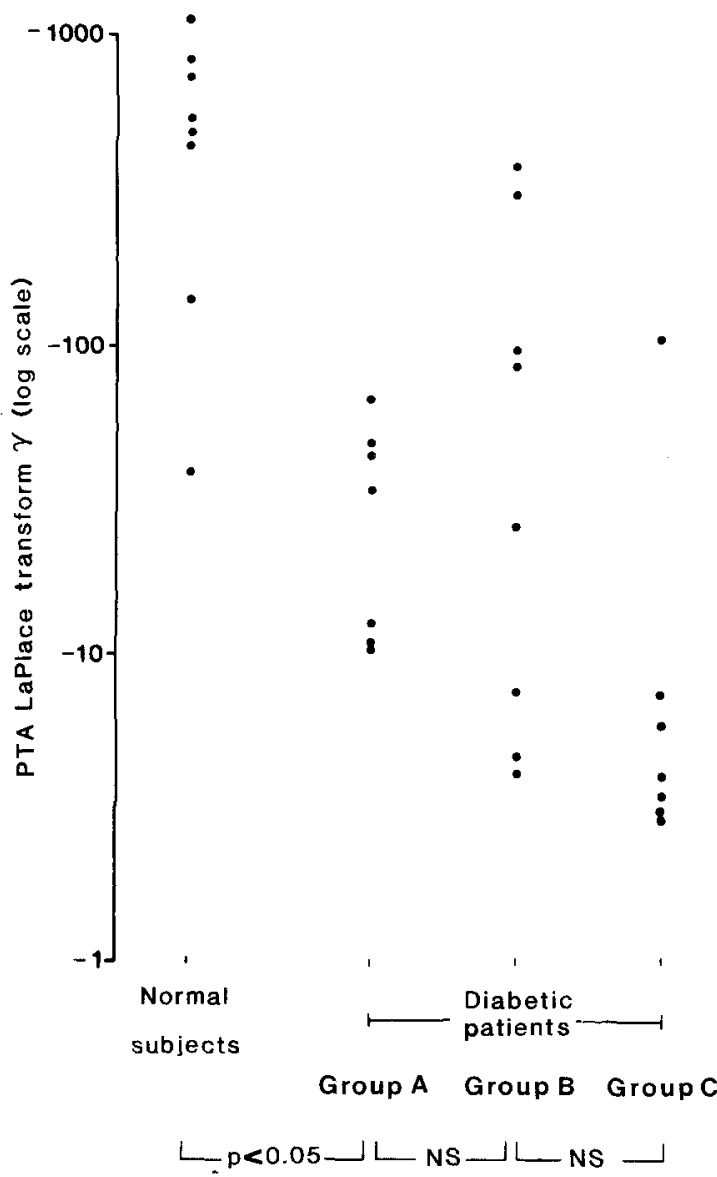

Fig. 2. Values for posterior tibial artery (PTA) Laplace transform Gamma derived by combining results from both limbs are illustrated for each group

\section{Discussion}

In this study, we have confirmed the presence of abnormal blood flow in the feet of diabetic patients with polyneuropathy by analysis of doppler waveforms from the posterior tibial artery. Analysis by two independent methods, pulsatility index and Laplace transform damping, indicated a pattern of blood flow consistent with reduced peripheral resistance. No difference was found in the blood flow abnormality between diabetic patients asymptomatic of neuropathy (Group A) and patients with chronic painful polyneuropathy (Group B). The most severe abnormalities were recorded in diabetic patients in Group $\mathrm{C}$ who had painless polyneuropathy and a history of recurrent foot ulceration. This latter finding is in agreement with previous studies of doppler waveforms analysed by the pulsatility index method from both the posterior tibial and dorsalis pedis arteries $[8,9]$.

There is evidence that arterio-venous shunting is the mechanism by which this abnormal pattern of blood flow arises in the diabetic foot and sympathetic deneveration has been proposed as the principal cause [10]. Distal sympathetic dysfunction usually reflects vagal dysfunction in diabetic neuropathy [28], so that one might expect the degree of blood flow abnormality to parallel abnormality in cardiac autonomic function tests. We have shown previously [25] and confirmed in this study that the degree of cardiovascular autonomic dysfunction in the two groups of diabetic patients symptomatic of neuropathy is the same; however, the blood flow abnormality in Group C (painless polyneuropathy with foot ulceration) was more severe, with one exception, than in Group B (chronic painful neuropathy), so that we did not find parallel changes in blood flow and autonomic disturbance. In diabetic patients asymptomatic of neuropathy, in whom we found evidence of only very mild autonomic dysfunction, there was evidence of abnormal blood flow indistinguishable from that found in patients with chronic painful polyneuropathy. Other vasomotor abnormalities, which could also conceivably be due to sympathetic neuropathy, have been reported in the feet of diabetic patients asymptomatic of neuropathy [6,9]. Thus, it may be that sympathetic neuropathy is only partly responsible for the blood flow abnormality; non-neuropathic factors, such as very small vessel occlusion, may also be relevant. Alternatively, the blood flow indices measured may be sensitive indicators of the sympathetic denervation which is known to be a prominent feature of diabetic polyneuropathy [29].

Proximal large vessel disease, by causing peripheral vasodilatation, may give rise to similar blood flow abnormalities in distal arteries. Accordingly we were careful to exclude occlusive vascular disease using sensitive non-invasive techniques. These have been adequately validated by others and included measurement of resting ankle/arm systolic pressure indices [23] and 
Table 5. The results of posterior tibial artery doppler waveform analysis by two methods are presented by group

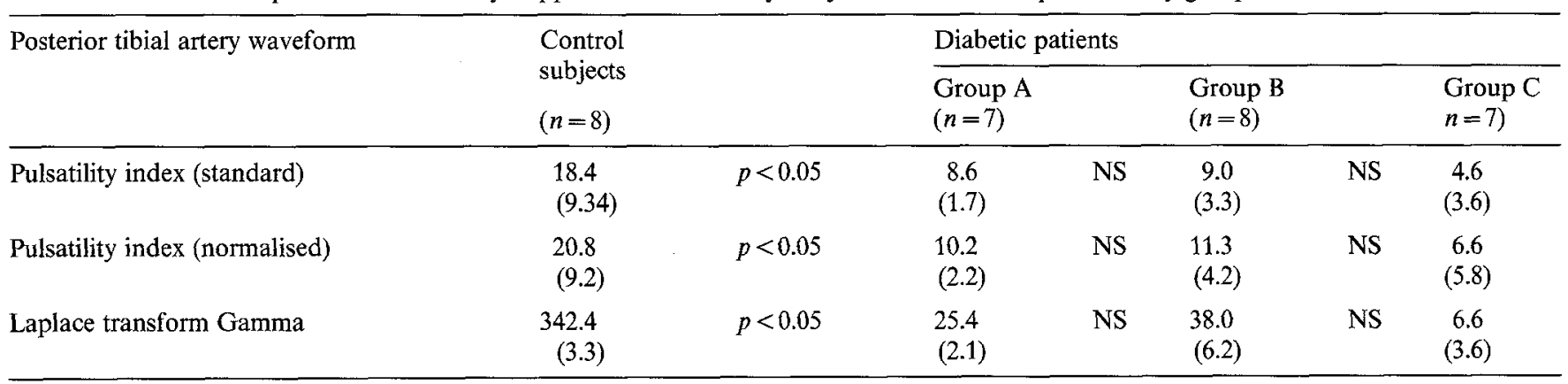

Table 6. X-ray abnormalities in the diabetic patients

\begin{tabular}{lllll}
\hline \multirow{2}{*}{ Arterial calcification } & \multicolumn{3}{l}{ Diabetic patients } \\
\cline { 3 - 5 } & $\begin{array}{l}\text { Group A } \\
(n=7)\end{array}$ & $\begin{array}{l}\text { Group B } \\
(n=6)\end{array}$ & $\begin{array}{l}\text { Group C } \\
(n=7)\end{array}$ \\
\hline Tibial & Mild & 3 & 0 & 0 \\
& Moderate & 2 & 3 & 2 \\
\multirow{2}{*}{ Metatarsal/ } & Severe & 0 & 1 & 2 \\
tarsal & Mild & 1 & 1 & 1 \\
\multirow{2}{*}{ Charcot's arthropathy } & Moderate & 1 & 2 & 2 \\
\hline
\end{tabular}

analysis of common femoral artery waveforms by the Laplace transform damping method [20].

In the current study, arterial wall calcification, which affects vascular compliance and hence could influence blood flow, was equally common and severe in patients with chronic painful polyneuropathy (Group B) as in those with recurrent foot ulceration and painless polyneuropathy (Group C). Other investigators have argued that arterial wall calcification is due to sympathetic denervation [30]. If true this would reinforce the idea that autonomic nerve damage is equivalent in the two neuropathic groups studied here and support the hypothesis that non-neuropathic factors may be involved in causing abnormal blood flow.

In conclusion, blood flow abnormality in the foot appears to be very common among all diabetic patients including those asymptomatic of neuropathy, but is most severe in those with chronic painless polyneuropathy and foot ulceration. There was no clear relationship with autonomic neuropathy (or vascular calcification) suggesting that factors other than sympathetic denervation should be considered in explaining the blood flow abnormality in the feet of diabetic patients.

Acknowledgements. We would like to that Ms. C. Macintyre, Department of Medical Statistics and Computing, Edinburgh University for help with statistical analysis, Mr. D. Bird, University Department of Surgery for help with doppler techniques and Ms. T. Butler for secretarial assistance and Dr. S.Chambers, Department of Radiology, Royal Infirmary of Edinburgh for assessing the radiographs.

\section{References}

1. Christensen NJ (1969) Spontaneous variations in resting blood flow, post-ischaemic peak flow and vibratory perception in diabetes. Diabetologia 5: 171-178

2. Partsch H (1978) Neuropathien vom ulzero-mutilierenden Typ, Klinik, Klassifikation, Durchblutungsmessungen. Z Gefäßkr [Suppl 6]: 1-48

3. Scarpello JHB, Martin TRP, Ward JD (1980) Ultrasound measurements of pulse-wave velocity in the peripheral arteries of diabetic subjects. Clin Sci 58:53-57

4. Edmonds ME, Nicholaides K, Watkins PJ (1986) Autonomic neuropathy and diabetic neuropathic foot ulceration. Diabetic Med 3: 56-59

5. Boulton AJM, Scarpello JHB, Ward JD (1982) Venous oxygenation in the diabetic neuropathy foot: evidence of ateriovenous shunting. Diabetologia 22:6-8

6. Rayman G, Hassan A, Tooke JE (1986) Blood flow in the skin of the foot related to posture in diabetes mellitus. Br Med J 292: $87-90$

7. Ward JD (1982) The diabetic leg. Diabetologia 2: 141-147

8. Edmonds ME, Wilton GN, Roberts VC, Watkins PJ (1983) Blood flow in the neuropathic limb of the diabetic. In: Taylor DEM, Stevens AL (eds) Blood flow: theory and practice. Academic, London, pp 157-171

9. Archer AG, Roberts VC, Watkins PI (1984) Blood flow patterns in painful diabetic neuropathy. Diabetologia 27:563-567

10. Watkins PJ, Edmonds ME (1983) Sympathetic nerve failure in diabetes. Diabetologia 25: 73-77

11. Gosling RG, Dunbar G, King DH, Newman DL, Side CD, Woodcock JP, Fitzgerald DE, Keates JS, Macmillan D (1971) The quantitative analysis of peripheral arterial disease by a noninvasive quantitative doppler waveform analysis. Br J Surg 68: 789-792

12. Skidnore R, Woodcock JP, Wells PNT, Bird D, Baird RN (1980) Physiological interpretation of doppler-shift waveforms III. Clinical Results. Ultrasound Med Biol 6: 227-231

13. Skidmore R, Woodcock JP (1980) Physiological interpretation of doppler-shift waveforms - I. Theoretical considerations. Ultrasound Med Biol 6:7-10

14. Skidmore R, Woodcock JP (1980) Physiological interpretation of doppler-shift waveforms. - II. Validation of the Laplace transform method for characterisation of the common femoral blood velocity/time waveform. Ultrasound Med Biol 6: 219-225

15. Evans DH, Macpherson DS, Bentley S, Asher MJ, Bell PRF (1981) The effect of proximal stenosis on doppler waveforms; a comparison of three methods of waveform analysis in an animal model. Clin Phys Physiol Meas 2(1): 17-25

16. Campbell WB, Cole SEA, Skidmore R, Baird RN (1984) The clinician and the vascular laboratory in diagnosis of aorto-iliac stenosis. Br J Surg 71: 302-306

17. Bird DR, Skidmore R, Woodcock JP (1980) The value of doppler transform function analysis in the diagnosis of aorto-iliac arterial occlusive disease. In: Baird RN, Woodcock JP (eds) Diagnosis 
and monitoring in arterial surgery. John Wright, Bristol, pp121-126

18. Baker JD, Machleder HI, Skidmore R (1984) Analysis of femoral artery doppler signals by Laplace transform damping method. J Vasc Surg 1: $520-524$

19. Law YF, Graham JC, Cotton LT, Roberts VC (1984) Validity of the transfer function model of the human arterial system of the lower limbs in man. Med Biol Eng Comput 22: 537-542

20. Macpherson DS, Evans DH, Bell PRF (1984) Common femoral artery doppler waveforms: a comparison of three methods of objective analysis with direct pressure measurements. Br J Surg 71: $46-49$

21. Yao ST, Hobbs JT, Irvine WT (1969) Ankle systolic pressure measurements in arterial disease affecting the lower extremities. Br J Surg 56: 676-679

22. Yao ST (1970) Haemodynamic studies in peripheral arterial disease. Br J Surg 57: 761-766

23. Osmundson PJ, Chesebro JH, O'Fallon WM, Zimmerman BR, Kazmier FJ, Palumbo PJ (1981) A prospective study of peripheral occlusive arterial disease in diabetes. II. Vascular laboratory assessment. Mayo Clin Proc 56: 223-232

24. Ewing DJ, Clarke BF (1982) Diagnosis and management of diabetic autonomic neuropathy. Br Med J 285: 916-918

25. Young RJ, Zhou YQ, Rodriguez E, Prescott RJ, Ewing DJ, Clarke BF (1986) Variable relationship between peripheral so- matic and autonomic neuropathy in patients with different syndromes of diabetic polyneuropathy. Diabetes 35: 192-197

26. Deanfield JE, Daggett PR, Harrison MJG (1980) The role of autonomic neuropathy in diabetic foot ulceration. J Neurol Sci 47: 203-210

27. Ahmed ME, Delbridge L, Le Quesne LP (1986) The role of autonomic neuropathy in diabetic foot ulceration. $\mathbf{J}$ Neurol Neurosurg Psychiat 49: 1002-1006

28. Low PA, Zimmerman BR, Dyck PJ (1986) Comparison of distal sympathetic with vagal function in diabetic neuropathy. Muscle Nerve 9: 592-596

29. Fagius $\mathbf{J}$ (1982) Microneurographic findings in diabetic polyneuropathy with special reference to sympathetic nerve activity. Diabetologia $23: 415-420$

30. Edmonds ME, Morrison N, Laws JW, Watkins PJ (1982) Medial arterial calcification in diabetes mellitus. Br Med J 284: 928-930

Received: 20 December 1986

and in revised form: 13 May 1987

Dr. D.O.C.Corbin

Department of Neurology

Queen Elizabeth Hospital

Birmingham B152TH

UK 